\section{Histochemistry as a unique approach for investigating normal and osteoarthritic cartilage}

\author{
G. Musumeci, ${ }^{1}$ P. Castrogiovanni, ${ }^{1}$ \\ V. Mazzone, ${ }^{2}$ M. A. Szychlinska, ${ }^{1}$ \\ S. Castorina, ${ }^{1}$ C. Loreto'
}

'Department of Bio-Medical Sciences, Human Anatomy and Histology Section,

School of Medicine, University of Catania 2Department G.F. Ingrassia, Anatomy, School of Medicine, University of Catania, Italy

\section{Abstract}

In this review article, we describe benefits and disadvantages of the established histochemical methods for studying articular cartilage tissue under normal, pathological and experimental conditions. We illustrate the current knowledge on cartilage tissue based on histological and immunohistochemical aspects, and in conclusion we provide a short overview on the degeneration of cartilage, such as osteoarthritis. Adult articular cartilage has low capacity to repair itself, and thus even minor injuries may lead to progressive damage and osteoarthritic joint degeneration, resulting in significant pain and disability. Numerous efforts have been made to implement the knowledge in the study of cartilage in the last years, and histochemistry proved to be an especially powerful tool to this aim.

\section{Introduction}

Bone and cartilage are highly specialized connective tissues that are engineered by nature to perform a variety of specialized tasks. ${ }^{1,2}$ As a result, these tissues have unique cellular constituents and ultrastructural organization that help to optimize the biochemical demands and biomechanical loads in vivo.,4 Our knowledge of these connective tissues has increased over the last century, and progress continues, as the ultrastructural and mechanical properties of bone and cartilage are a dynamic area that is constantly evolving with new insight: in this research field, histochemical and immunohistochemical techniques apparently plaid a major role. In this review, the cellular constituents and the ultrastructural organization of cartilage will be considered, in the context of recent experimental and theoretical studies.

\section{Cartilage}

Hyaline cartilage is a flexible connective tissue, found in many areas of human and other vertebrate bodies, that covers the opposing osseous ends of every diarthrodial human joint, ${ }^{5,6}$ and in the growth plate of the metaphysis. ${ }^{7-11}$ To protect the underlying bone, articular cartilage allows a continuous and almost frictionless movement of the bony skeleton over years. $^{5,6}$ In the knees, one of the protection mechanisms against cartilage wear comes from the presence of the two menisci. ${ }^{12-14}$

Cartilage tissue is composed of specialized cells called chondroblasts and chondrocytes, and has unique viscoelastic and compressive properties provided by the extracellular matrix..$^{15}$ The latter is mainly composed of collagen type II and abundant ground substance, rich in proteoglycan aggrecans and elastin fibers. ${ }^{16}$ Type II collagen is responsible for the tensile strength of the cartilage, while aggrecan provides the osmotic resistance for cartilage to withstand compressive loads. ${ }^{16}$

According to the amount of these components, cartilage is classified into three types: elastic cartilage, fibrocartilage and hyaline cartilage. Histologically, elastic cartilage resembles hyaline cartilage, with a dense network of finely branched elastic fibers. Fibrous cartilage, unlike other types of cartilage, contains mainly type I collagen. It may be found in the intraarticular lips, disks, menisci, and intervertebral discs, and it serves as transitional tissue between dense connective tissue (tendon) and hyaline cartilage. ${ }^{17-22}$ The chondrocytes in the hyaline cartilage are located in lacunae within the matrix (forming chondrons together with the pericellular matrix) and represent only $5 \%$ to $10 \%$ of the total cartilage volume, but they are crucial to the maintenance of a stable extra cellular matrix..$^{5,6}$ Nutrients and cellular repair components are transported to the chondrocytes by diffusion from the synovial fluid, helped by the pumping action generated by different joint movement of the articular cartilage. ${ }^{5,6}$

Thanks to histochemistry and microscopy, it is possible to highlight the characteristic organization of articular cartilage that shows a heterogeneous distribution of cell and matrix components through its width. Four zones are evident in it (Figure 1): superficial zone, intermediate (or middle zone), radial zone (or deep zone) and calcified cartilage (or calcified zone). There is a superficial zone, where chondrocytes produce and lay mainly collagen type II in a parallel direction to the surface of the tissue; a middle zone characterized by randomly oriented collagen fibers; a deep zone, located at the cartilage-bone interface where the collagen fibers are aligned perpendicular to the surface; and the calcified zone..$^{23}$ The superficial zone con-
Correspondence: Dr. Giuseppe Musumeci, Department of Bio-Medical Sciences, Human Anatomy and Histology Section, School of Medicine, University of Catania, Via S. Sofia 87, 95123 Catania, Italy. Tel. +39.095 .3782043 - Fax: +39.095.3782034. E-mail: g.musumeci@unict.it

Keywords: cartilage, knee arthroplasty, osteoarthritis, histology, histochemistry, immunohistochemistry.

Contributions: GM, planning, manuscript design, execution, analysis of the study, results discussing, manuscript writing; SC, PC, execution and analysis of the study; VM, MAS, execution of the study; CL, study execution, manuscript discussing, planning and proofreading.

Conflict of interests: the authors declare no conflict of interests.

Acknowledgments: the study was funded by the Department of Bio-Medical Sciences, University of Catania. The authors would like to thank Prof. Iain Halliday for commenting and making corrections to the paper. The authors wish to remember their late colleague Prof. M.L. Carnazza, who worked with them on this project before her premature death.

Received for publication: 10 January 2014.

Accepted for publication: 11 March 2014.

This work is licensed under a Creative Commons Attribution NonCommercial 3.0 License (CC BYNC 3.0).

(C) Copyright G. Musumeci et al., 2014

Licensee PAGEPress, Italy

European Journal of Histochemistry 2014; 58:2371 doi:10.4081/ejh.2014.2371

tains the highest proportion of collagen, which results in the high tensile modulus of the tissue and indicates that the main function is to resist the shear stress at the joint surface. The middle zone contains more proteoglycans, which exhibit repulsive negative charges that are neutralized by positive ions, leading to swelling pressures and its highly stable hydrated structure. ${ }^{24}$ These proteoglycans are responsible for the hyaline cartilage's distinctive compressionresistance properties, due to the increasing drag forces between the fluid and the matrix, that maintain the fluid within the tissue as the cartilage is compressed ${ }^{25}$ As a consequence, hyaline cartilage of the joint becomes stiffer as the rate of loading increases..$^{26}$ Due to its intrinsic organization, hyaline cartilage presents a high compressive modulus; consistently, biomaterials designed with nonlinear, inhomogeneous, and viscoelastic properties that imitate the behavior of native hyaline cartilage are most likely to succeed in the functional repair of cartilage defects. ${ }^{27}$ 
Only small defects associated with minimal loss of matrix components can be regenerated by hyaline cartilage. Without any neural, lymphatic or vascular supply, cartilage resists heavy mechanical load over years without degenerative changes. ${ }^{5,6}$ Due to its unique properties, cartilage shows little or no intrinsic capacity for an effective healing response. More extensive defects exceed the repair capacity and consequently the damage becomes permanent.

\section{Osteoarthritis}

Osteoarthritis (OA) is one of the most relevant diseases of high social and economical importance in the field of orthopedics, and it is worldwide the joint disease with the highest prevalence. ${ }^{28-31}$ It also influences disability in middle-age and older populations, especially in developing countries. In advanced stages, the patients suffer from severe pain and restriction of mobility. ${ }^{28-31}$ The consequence in many cases is an inability to work and often the substitution of the diseased joint with an artificial implant (arthroplasty) becomes inevitable.

Typical features of $\mathrm{OA}$ are the degeneration or progressive loss of the structure and functionality of articular cartilage. The precise mechanism of cartilage degradation in $\mathrm{OA}$ is still unclear, but a complex interplay of genetic, environmental, metabolic and biochemical factors is proposed. As cartilage tissue itself has only very limited capacities of self-renewing, the development of this disorder is chronic and progressive. ${ }^{28-31}$ Generally, OA is diagnosed in more advanced stages, when clinical and radiographic (X-rays, MRI, Arthroscopic surgery) signs become evident (Figures 2 and 3 ). At this point the options for therapeutic intervention without surgery are limited. It is, therefore, crucial to elucidate the physiopathology in the course of $\mathrm{OA}$ and especially in early stages, to develop new diagnostic and therapeutic strategies.

Numerous studies on human osteoarthritic tissue and in animal models have addressed various aspects of $0 \mathrm{~A}$ progression to get a better understanding of the pathophysiology of this disease. OA is classically defined as a progressive degenerative rather than an inflammatory disease, and it is characterized by deterioration of joints, including loss of articular cartilage and subchondral bone, as well as osteophyte formation which lead to chronic pain and functional restrictions in the affected joints (Figure 4)..$^{28-31}$ Different factors can be involved in the development of $\mathrm{OA}$ : mostly traumatic events are causative, but there are other factors like genetic predisposition, defective position of joints, ageing and malnutrition, which all lead to similar alterations in the joint cartilage. The primary

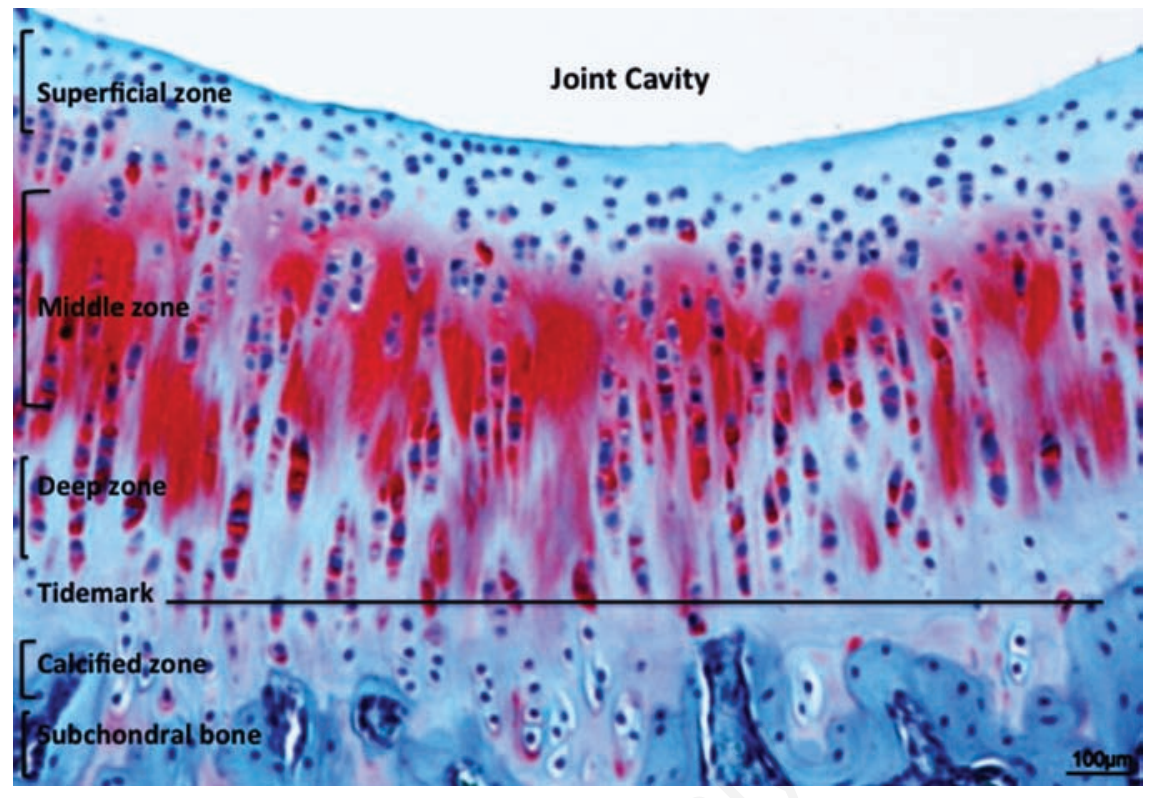

Figure 1. Safranin-O staining (cartilaginous proteoglycans detection) of the healthy hyaline cartilage layers. Scale bars: $100 \mu \mathrm{m}$.
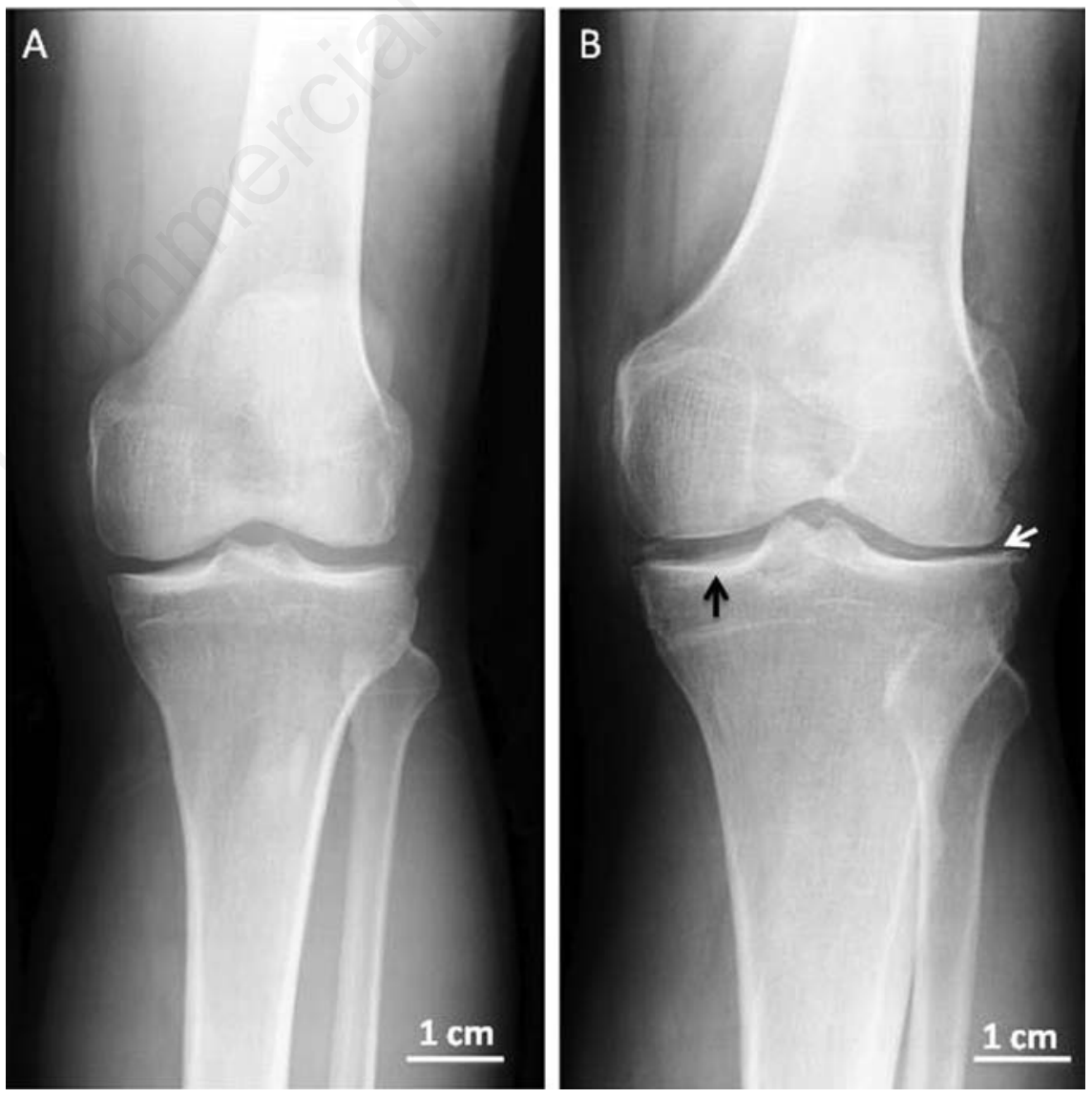

Figure 2. Xray anteroposterior projection in left normal and osteoarthritic knees from two different adult patients. A) Left normal knee. B) Left osteoarthritic knee, in the Xray there are radiographically visible changes such as narrowed joint space (white arrow) and thickening (black arrow) of the articular cartilage. Scale bars: $1 \mathrm{~cm}$. 
symptoms associated with $0 \mathrm{~A}$ include: pain (mild, moderate, or severe), stiffness, limited range of motion of the joint, localized swelling. ${ }^{32}$ It is known that $\mathrm{OA}$ is the result of mechanical and biological processes that modify cartilage homeostasis. Under physiological conditions, chondrocytes maintain equilibrium between the synthesis and degradation of extra cellular matrix components, thus regulating the structural and functional integrity of cartilage. , $, 6,28-31$

Articular cartilage homeostasis is the result of an intricate interplay between anabolic and catabolic, anti- and pro-inflammatory, anti- and pro-apoptotic activities. ${ }^{5,6,28-31}$ Chondrocytes represent the versatile regulators of this cartilage equilibrium. As a reaction to cartilage loss the newly formed tissue is mostly fibrous (major expression of type I collagen and too small amounts of aggrecan), and the mechanical capacities are significantly reduced compared to healthy hyaline cartilage. So, therapeutic intervention is needed to improve the quality of the regenerate cartilage. It is of crucial importance to know about the features and underlying molecular mechanisms of cartilage destruction in $\mathrm{OA}$ in order to develop and improve diagnostic and therapeutic approaches. A major problem in OA research is that the disease is mostly not diagnosed until the progressed and pronounced alterations in the joint lead to pain and to radiographically detectable changes. Cartilage tissue from early stage $0 \mathrm{~A}$ is not easily available since the disease is usually not clinically apparent. For this reason a number of animal models of OA have been developed to examine the early features of cartilage degeneration. ${ }^{14}$ Today, tissue engineering is a widely studied alternative to avoid knee replacement surgery in 0 A. $1,6,23,25,29-31$

\section{Histological and histochemical techniques for studying articular cartilage}

Microscopy and histochemical techniques obviously represent an especially suitable approach to investigate in situ the heterogeneous distribution of cell and matrix components through the cartilage width.

Histological evaluation and characterization of cartilage tissue under normal and pathological condition is normally done with light microscopy. Descriptive histology and histomorphometry are two main types of histological study. ${ }^{33,34}$ Depending on the particular situation, either method or both may be used. Descriptive histology is used to provide a general evaluation of the tissue of interest, including the morphology, structure, and arrangement of cells, matrix, implant, or tissue-implant interface.$^{35}$ Scoring

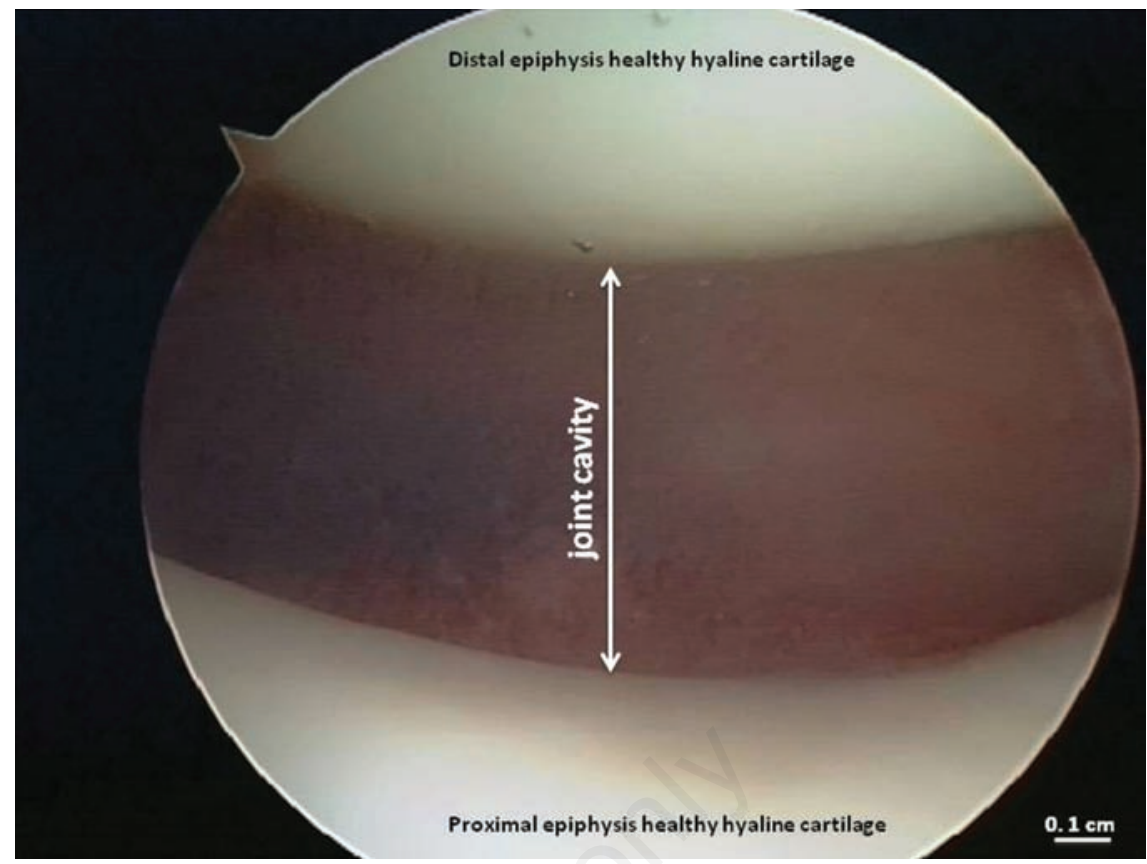

Figure 3. Arthroscopic image of the healthy hyaline cartilage from knee joint. Scale bar: $0.1 \mathrm{~cm}$.
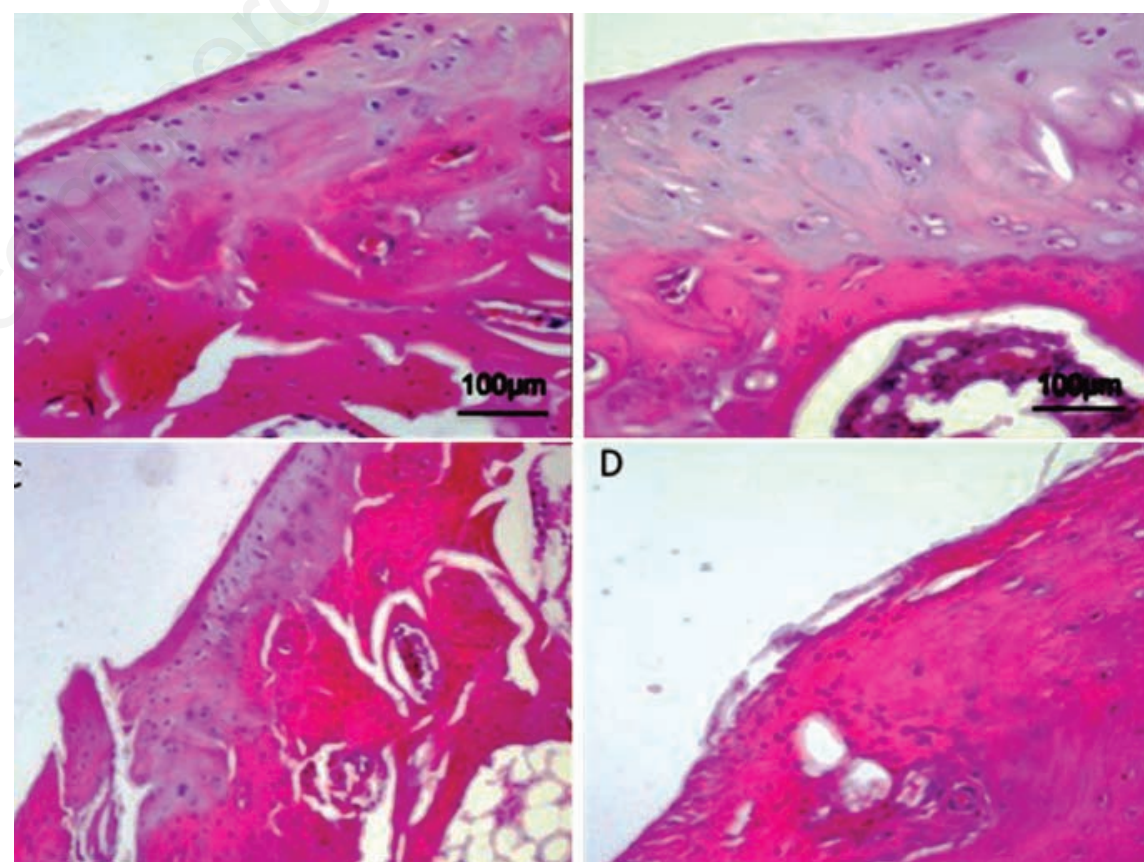

Figure 4. Articular knee cartilage from donors. Hematoxylin and Eosin staining. A) Normal articular knee cartilage; cells in the superficial zone are small and flat; cells in the middle and deep zone are arranged in columns; the tidemark is intact. B, C) Articular knee cartilage at early OA stage; moderate OA cartilage, the structure of the collagen network is damaged, which leads to reduced thickness of the cartilage; the tidemark is almost intact. D) Articular knee cartilage at advanced OA stage, due to aging; severe OA cartilage, cells are arranged in clusters especially around fissures or disappear completely as the disease progresses; the organization of cartilage is completely disordered and replaced by fibrocartilaginous, scar-like tissue with fibroblast like cells. Scale bars: $100 \mu \mathrm{m}$. 
systems are often designed in order to semiquantify the components of interest. An example of this is the estimation of $\mathrm{OA}$ in cartilage tissue:28-31 advanced OA is scored as 3, moderate as 2 , mild as 1 , and no $0 \mathrm{~A}$ as 0 . The data are analysed using nonparametric analyses of variance. Example of other similar scoring system can be found in the literature for evaluation of fracture healing, articular cartilage repair, and biocompatibility of implants in soft tissue. ${ }^{9}$ Many staining methods are available. The classic hematoxylin and eosin staining remains the basic and most commonly used procedure, and can be used for both decalcified and undecalcified specimens..$^{20,28,36}$ Both Goldner's trichrome staining and the von Kossa staining allow differentiation of osteoid from mineralized bone matrix, although von Kossa staining provides little additional information. Other common stainings for bone sections are used. Giemsa, toluidine blue (often used for ground sections), methylene blue/basic fuchsin and Masson's trichrome are suitable to evaluate the presence of acidophilic bone tissue; Alizarin-S staining is appropriate to distinguish bone from the calcified matrix; the periodic acid-Schiff reaction is used to evaluate the presence of pathological tissue. ${ }^{20,28,34,36}$ In the evaluation of articular cartilage, stainings such as safranin 0/fast green (for glycosaminoglycans), alcian blue (for proteoglycans), and periodic acid-Schiff (for chondroitin sulphate and glycoproteins) are commonly used. Lastly, Goldner's or Masson's trichrome are useful for both bone and cartilage staining in paraffin-embedded sections. ${ }^{12,28,31,34,36}$

Staining procedure and more specialized histochemistry are performed to obtain specific types of information about bone, cartilage and relative extracellular matrix, under normal and pathological condition, $, 2,28,31,34,36$ and in recent years the immunohistochemical techniques have been expressly applied. Unfortunately, all the different features of the cartilage tissue cannot usually be examined by one single staining procedure or localization method, and thus the specific needs of a project must be clearly defined at the onset of specimen preparation. If bone formation and mineralization are important for the study, then the specimens must be processed in an undecalcified method and sectioned with special microtomes and knives. If more routine histologic staining and localization are the desired outcome, then decalcification procedures can be performed to embed the specimen in paraffin. ${ }^{34-37} \mathrm{~A}$ good experimental plan, which may even include a pilot study, should include a carefully chosen fixative agent. Alcohol retains tetracycline labels, and is still used by some investigators, yet it does not provide good cellular preservation. Ten percent neutral buffered formalin is a commonly used fixative, but the length of time that bone is kept in this solution must be carefully controlled because overexposure can block alkaline phosphatase localization in osteoblasts and may also interfere with specialized immunolocalizations, for e.g. the RANKL-OPG antibodies. ${ }^{34-37}$ It is also important to ensure that the fixative penetrates the entire bone specimens. These techniques are used also for examining the biochemical composition of cartilage, ligament, tendon and other tissues ${ }^{38,39}$ Immunostaining can be used to identify types I, II, III collagen, glycoproteins, laminin, tenasin, and fibronectin in plastic- or paraffin-embedded specimens. Common macromolecules such as cartilage matrix protein, types I, II and III collagen, and proteoglycans have also been successfully localized in cartilage specimens. Other cartilage and fibrocartilage biochemical markers for which immunohistochemical staining methods have been developed include types V, VI, X and XI collagen chondroitin sulphate, keratin sulfate, stromelysin, tumor necrosis factor- (Tnf- ), TNF receptors, fibronectin, AQPs, RUNX, ST2, ILs, MMPs, apoptosis markers, -defensin, lubricin and many others. ${ }^{12-18,21,28-31,33,34,40-48 .}$

\section{Concluding remarks}

In conclusion, we can assert that thanks to routine staining procedure and more specialized histochemistry, it is possible to obtain specific informations on both physiological and pathological articular cartilage. Furthermore, specific immunohistochemical techniques are now suitable. As already said, OA is often diagnosed in advanced stages, and with this narrative review, we wished to underline how crucial is to know more and more about the physiopathology in the course and especially in early stages of OA to develop new diagnostic and therapeutic strategies.

\section{References}

1. Gigante A, Manzotti S, Bevilacqua C, Orciani M, Di Primio R, Mattioli-Belmonte M. Adult mesenchymal stem cells for bone and cartilage engineering: effect of scaffold materials. Eur J Histochem 2008;52: 169-74.

2. Nanci A, Wazen R, Nishio C, Zalzal SF. Immunocytochemistry of matrix proteins in calcified tissues: functional biochemistry on section. Eur J Histochem 2008;52:20114.

3. Shibata S, Sakamoto Y, Baba O, Qin C, Murakami G, Cho BH. An immunohistochemical study of matrix proteins in the craniofacial cartilage in midterm human fetuses. Eur J Histochem 2013;57:e39.
4. Narducci P, Bortul R, Bareggi R, Nicolin V. Clathrin-dependent endocytosis of membrane-bound RANKL in differentiated osteoclasts. Eur J Histochem 2010;54 :e6.

5. Musumeci G, Loreto C, Castorina S, Imbesi R, Leonardi R, Castrogiovanni P. Current Concepts in the Treatment of Cartilage Damage. A Review. Ital J Anat Embryol 2013;118:189-203.

6. Musumeci G, Loreto C, Castorina S, Imbesi R, Leonardi R, Castrogiovanni P. New perspectives in the treatment of cartilage damage. Poly(ethylene glycol) diacrylate (PEGDA) scaffold. A review. Ital J Anat Embryol 2013;118:204-10.

7. Pichler K, Musumeci G, Vielgut I, Martinelli E, Sadoghi P, Loreto C, Weinberg AM. Towards a better understanding of bone bridge formation in the growth plate - an immunohistochemical approach. Connect Tissue Res 2013;54:408-15.

8. Musumeci G, Castrogiovanni P, Loreto C, Castorina S, Pichler K, Weinberg AM. Posttraumatic caspase- 3 expression in the adjacent areas of growth plate injury site. A morphological study. Int $\mathrm{J}$ Mol Sci 2013;14:15767-84.

9. Pichler K, Kraus T, Martinelli E, Sadoghi P, Musumeci G, Uggowitzer PJ, Weinberg AM. Cellular reactions to biodegradable magnesium alloys on human growth plate chondrocytes and osteoblasts. Int Orthop. 2013 Nov 21. [Epub ahead of print].

10. Bradaschia-Correa V, Barrence FAC, Ferreira LB, Massa LF, Arana-Chavez VE. Effect of alendronate on endochondral ossification in mandibular condyles of growing rats. Eur J Histochem 2012;56: e24.

11. Shibata S, Fukuoka H, Sato R, Abe T, Suzuki Y. An in situ hybridization study of the insulin-like growth factor system in developing condylar cartilage of the fetal mouse mandible. Eur J Histochem 2012;56:e23.

12. Musumeci G, Carnazza ML, Leonardi R, Loreto $\mathrm{C}$. Expression of $\beta$-defensin-4 in "an in vivo and ex vivo model" of human osteoarthritic knee meniscus. Knee Surg Sports Traumatol Arthrosc 2012;20:216-22.

13. Musumeci G, Loreto C, Carnazza ML, Cardile V, Leonardi R. Acute injury affects lubricin expression in knee menisci. An immunohistochemical study. Ann Anat 2013;195:151-8.

14. Musumeci G, Leonardi R, Carnazza ML, Cardile V, Pichler K, Weinberg AM, Loreto C. Aquaporin 1 (AQP1) expression in experimentally induced osteoarthritic knee menisci: an in vivo and in vitro study. Tissue Cell 2013;45:145-52.

15. Lehmann M, Martin F, Mannigel $\mathrm{K}$, Kaltschmidt K, Sack U, Anderer U. Threedimensional scaffold-free fusion culture: 
the way to enhance chondrogenesis of in vitro propagated human articular chondrocytes. Eur J Histochem 2013;57:e31.

16. de Moraes LOC, Lodi FR, Gomes TS, Oshima CTF, Marques SR, Lancellotti CLP, Rodriguez-Vázquez JF, Mérida-Velasco JR, Alonso LG. Immunohistochemical expression of types I and III collagen antibodies in the temporomandibular joint disc of human fetuses. Eur J Histochem 2011;55:e24.

17. Kiga N, Tojyo I, Matsumoto T, Hiraishi Y, Shinohara Y, Makino S, Fujita S. Expression of lumican and fibromodulin following interleukin-1 beta stimulation of disc cells of the human temporomandibular joint. Eur J Histochem 2011;55:e11.

18. Loreto C, Almeida LE, Migliore MR, Caltabiano M, Leonardi R. TRAIL, DR5 and caspase 3-dependent apoptosis in vessels of diseased human temporomandibular joint disc. An immunohistochemical study. Eur J Histochem 2010;54:e40.

19. Matsumoto T, Inayama M, Tojyo I, Kiga N, Fujita S. Expression of hyaluronan synthase 3 in deformed human temporomandibular joint discs: in vivo and in vitro studies. Eur J Histochem 2010;54:e50.

20. Loreto C, Musumeci G, Castorina A, Martinez G. Degenerative disc disease of herniated intervertebral discs is associated with extracellular matrix remodeling, vimentin-positive cells and cell death. Ann Anat 2011;193:156-62.

21. Loreto C, Leonardi R, Musumeci G, Pannone G, Castorina S. An ex vivo study on immunohistochemical localization of MMP-7 and MMP-9 in temporomandibular joint discs with internal derangement. Eur J Histochem 2013;57:e12.

22. Kiga N, Tojyo I, Matsumoto T, Hiraishi Y, Shinohara Y, Fujita S. Expression of lumican related to CD34 and VEGF in the articular disc of the human temporomandibular joint. Eur J Histochem 2010;54:e34.

23. Johnstone B, Alini M, Cucchiarini M, Dodge GR, Eglin D, Guilak F, Madry H, Mata A, Mauck RL, Semino CE, Stoddart MJ. Tissue engineering for articular cartilage repairthe state of the art. Eur Cell Mater 2013;25:248-67.

24. Poole AR, Kojima T, Yasuda T, Mwale F, Kobayashi M, Laverty S. Composition and structure of articular cartilage - A template for tissue repair. Clin Orthop Relat Res 2001; 391:26-33.

25. Mow VC, Ratcliffe A, Poole AR. Cartilage and diarthrodial joints as paradigms for hierarchical materials and structures. Biomaterials 1992;13:67-97.

26. Park S, Hung CT, Ateshian GA. Mechanical response of bovine articular cartilage under dynamic unconfined compression loading at physiological stress levels. Osteoarthritis
Cartilage 2004;12:65-73.

27. Guilak F, Butler DL, Goldstein SA. Functional tissue engineering: the role of biomechanics in articular cartilage repair. Clin Orthop Relat Res 2001;391:295-305.

28. Musumeci G, Loreto C, Carnazza ML, Martinez G. Characterization of apoptosis in articular cartilage derived from the knee joints of patients with osteoarthritis. Knee Surg Sports Traumatol Arthrosc 2011;19:307-13.

29. Musumeci G, Carnazza ML, Loreto C, Leonardi R, Loreto C. $\beta$-defensin-4 (HBD4 ) is expressed in chondrocytes derived from normal and osteoarthritic cartilage encapsulated in PEGDA scaffold. Acta Histochem 2012;114:805-12.

30. Musumeci G, Loreto C, Carnazza ML, Coppolino F, Cardile V, Leonardi R. Lubricin is expressed in chondrocytes derived from osteoarthritic cartilage encapsulated in poly(ethylene glycol) diacrylate (PEGDA) scaffold. Eur J Histochem 2011;55:e31.

31. Musumeci G, Loreto C, Carnazza ML, Strehin I, Elisseeff J. OA cartilage derived chondrocytes encapsulated in poly(ethylene glycol) diacrylate (PEGDA) for the evaluation of cartilage restoration and apoptosis in an in vitro model. Histol Histopathol 2011;26:1265-78.

32. Merashly M, Uthman I. Management of knee osteoarthritis: an evidence-based review of treatment options. J Med Liban 2012;60:237-42.

33. Musumeci G, Loreto C, Leonardi R, Castorina S, Giunta S, Carnazza ML, et al. The effects of physical activity on apoptosis and lubricin expression in articular cartilage in rats with glucocorticoid-induced osteoporosis. J Bone Miner Metab 2013;3:274-84.

34. Pichler K, Loreto C, Leonardi R, Reuber T, Weinberg AM, Musumeci G. In rat with glucocorticoid-induced osteoporosis, RANKL is downregulated in bone cells by physical activity (treadmill and vibration stimulation training). Histol Histopathol. 2013;28:1185-96.

35. Teti G, Salvatore V, Ruggeri A, Manzoli L, Gesi M, Orsini G, et al. In vitro reparative dentin: a biochemical and morphological study. Eur J Histochem 2013;57:e23.

36. Musumeci G, Loreto C, Clementi G, Fiore $\mathrm{CE}$, Martinez G. An in vivo experimental study on osteopenia in diabetic rats. Acta Histochem. 2011;113:619-25.

37. Tetè S, Vinci R, Zizzari VL, Zara S, La Scala $\mathrm{V}$, Cataldi A, et al. Maxillary sinus augmentation procedures through equine-derived biomaterial or calvaria autologous bone: immunohistochemical evaluation of OPG/RANKL in humans. Eur J Histochem 2013;57:e10.
38. Orsini G, Ruggeri A, Mazzoni A, Nato F, Falconi M, Putignano A, et al. Immunohistochemical localization of dentin matrix protein 1 in human dentin. Eur J Histochem 2008;52:215-20.

39. Martini D, Trirè A, Breschi L, Mazzoni A, Teti G, Falconi M, et al. Dentin matrix protein 1 and dentin sialophosphoprotein in human sound and carious teeth: an immunohistochemical and colorimetric assay. Eur J Histochem 2013;57:e32.

40. Musumeci G, Trovato FM, Pichler K, Weinberg AM, Loreto C, Castrogiovanni P. Extra-virgin olive oil diet and mild physical activity prevent cartilage degeneration in an osteoarthritis model. An "in vivo" and "in vitro" study on lubricin expression. Journal of Nutritional Biochemistry 2013;24:206475 .

41. Loreto C, Lo Castro E, Musumeci G, Loreto F, Rapisarda G, Rezzani R, Castorina S, Leonardi R, Rusu MC. Aquaporin 1 expression in human temporomandibular disc. Acta Histochem 2012;114:744-8.

42. Loreto C, Galanti C, Almeida LE, Leonardi R, Pannone G, Musumeci G, et al. Expression and localization of aquaporin-1 in temporomandibular joint disc with internal derangement. J Oral Pathol Med 2012;41:642-47.

43. Leonardi R, Musumeci G, Sicurezza E, Loreto C. Lubricin in human temporomandibular joint disc: An immunohistochemical study. Arch Oral Biol 2012;57:61419.

44. Leonardi R, Almeida LE, Loreto C. Lubricin immunohistochemical expression in human temporomandibular joint disc with internal derangement. J Oral Pathol Med 2011;40:587-92.

45. Loreto C, Almeida LE, Trevilatto P, Leonardi R. Apoptosis in displaced temporomandibular joint disc with and without reduction: An immunohistochemical study. J Oral Pathol Med 2011;40: 103-10.

46. Leonardi R, Almeida LE, Trevilatto PC, Loreto $\mathrm{C}$. Occurrence and regional distribution of TRAIL and DR5 on temporomandibular joint discs: comparison of disc derangement with and without reduction. Oral Surg Oral Med Oral Pathol Oral Radiol Endod 2010;109:244-51.

47. Leonardi R, Loreto C, Barbato E, Caltabiano R, Muzio L. MMP-13 (collagenase 3) localization in human temporomandibular joint discs with internal derangement. Acta Histochem 2008;110:314-18.

48. Leonardi R, Loreto C, Barbato E, Polimeni A, Caltabiano R, Lo Muzio L. A histochemical survey of the human temporomandibular joint disc of patients with internal derangement without reduction. J Craniofac Surg 2007;18:1429-33. 